\title{
MicroRNA-101a Inhibits Cardiac Fibrosis Induced by Hypoxia via Targeting TGF $\beta$ RI on Cardiac Fibroblasts
}

\author{
Xin Zhao Kejing Wang Yuhua Liao Qiutang Zeng Yushu Li Fen Hu Yuzhou Liu \\ Kai Meng Cheng Qian Qing Zhang Hongquan Guan Kaige Feng You Zhou
}

Yimei Du Zhijian Chen

Laboratory of Cardiovascular Immunology, Institute of Cardiology, Union Hospital, Tongji Medical

College, Huazhong University of Science and Technology, Wuhan, PR China

\section{Key Words}

Cardiac fibroblasts $\bullet$ Hypoxia $\bullet$ MicroRNAs $\bullet$ Transforming growth factor $\beta$ receptor I $\bullet$ Cardiac fibrosis

\begin{abstract}
Background/Aims: Hypoxia is a basic pathological challenge that is associated with numerous cardiovascular disorders including aberrant cardiac remodeling. Transforming growth factor beta (TGF- $\beta$ ) signaling pathway plays a pivotal role in mediating cardiac fibroblast (CF) function and cardiac fibrosis. Recent data suggested that microRNA-101a (miR-101a) exerted anti-fibrotic effects in post-infarct cardiac remodeling and improved cardiac function. This study aimed to investigate the potential relationship between hypoxia, miR-101a and TGF- $\beta$ signaling pathway in CFs. Methods and Results: Two weeks following coronary artery occlusion in rats, the expression levels of both TGF $\beta 1$ and TGF $\beta$ RI were increased, but the expression of miR-101a was decreased at the site of the infarct and along its border. Cultured rat neonatal CFs treated with hypoxia were characterized by the up-regulation of TGF $\beta 1$ and TGF $\beta R I$ and the down-regulation of miR-101a. Delivery of miR-101a mimics significantly suppressed the expression of TGF $\beta R I$ and $p-S m a d$ 3, CF differentiation and collagen content of CFs. These anti-fibrotic effects were abrogated by co-transfection with AMO-miR-101a, an antisense inhibitor of miR-101a. The repression of TGF $\beta R I$, a target of miR-101a, was validated by luciferase reporter assays targeting the 3'UTR of TGFBRI. Additionally, we found that overexpression of miR-101a reversed the improved migration ability of CFs and further reduced CF proliferation caused by hypoxia. Conclusion: Our study illustrates that miR-101a exerts anti-fibrotic effects by targeting TGF $\beta R I$, suggesting that miR-101a plays a multi-faceted role in modulating TGF- $\beta$ signaling pathway and cardiac fibrosis.
\end{abstract}




\section{Cellular Physiology and Biochemistry}

Cell Physiol Biochem 2015;35:213-226

\begin{tabular}{l|l}
\hline DOI: $10.1159 / 000369689$ & C 2015 S. Karger AG, Basel
\end{tabular}

Published online: January 09, $2015 \quad$ www.karger.com/cpb

Zhao et al.: MiRNA-101a Targets TGFBRI on CFs

\section{Introduction}

Cardiovascular diseases constitute a leading cause of death worldwide. Extracellular matrix (ECM) metabolic imbalance is involved in various cardiovascular diseases such as heart failure, atrial fibrillation and myocardial infarction (MI), and may lead to pathological cardiac remodeling [1, 2]. Accounting for $60 \%-70 \%$ of cells in human heart, cardiac fibroblasts (CFs) are the most prevalent cell type and play an essential role in both ECM metabolism and cardiac fibrosis, which is an important part of cardiac remodeling $[1,3]$.

The progression of cardiovascular diseases is usually associated with numerous stimuli, including ischemia, inflammation, and pressure or volume overload, all of which may induce cardiac fibrosis. A common player among these pathological stimuli is hypoxia, which may directly result from a lack of oxygen or indirectly from increased oxygen depletion caused by activated resident cells or infiltrated inflammatory cells. Therefore, prolonged hypoxia may play a critical role in aberrant cardiac remodeling in cardiovascular diseases [4-6].

Transforming growth factor beta (TGF- $\beta$ ) signaling pathway plays a pivotal role in modulating CF function and the progression of cardiac fibrosis [7]. TGF $\beta 1$ exerts biological effects on CFs by interacting with a complex of trans-membrane serine/threonine kinase receptors (TGF $\beta$ RI/TGF $\beta$ RII) that phosphorylate and activate Smad 2/3; these Smads subsequently form a functional transcription complex with Smad 4. This trimeric complex elicits transcription responses on target genes by associating with high affinity DNA binding transcription factors or regulatory promoter sequences [8]. TGF $\beta$ receptor levels could regulate the specificity of the signaling pathway's activation and the biological effects of TGF 1 19-11]. Previous studies have demonstrated that inhibiting TGF $\beta$ RI with a TGF $\beta$ RI inhibitor significantly attenuated left ventricular remodeling and improved systolic dysfunction in rat MI models [12].

MicroRNAs (miRNAs, miRs) are a class of endogenous, small (19-25 nucleotides), non-coding RNAs that repress translation or induce degradation of target gene mRNA by binding with 3'-untranslated regions (3'-UTR) of the target genes [13]. miRs are tissue- and cell-specific, and accumulating evidence has demonstrated that miRs play important roles in many cardiac diseases, including arrhythmia, cardiac hypertrophy, and heart failure [1418]. Some miRs, including miR-21 [19], miR-29 [20] and miR-24 [21] have been proved to affect cardiac remodeling via regulating TGF $\beta$-TGF $\beta$ RI/TGF $\beta$ RII-Smad axis. A recent study [22] showed that miR-101a could attenuate cardiac interstitial fibrosis and improve left ventricular compliance in rat MI models by down-regulating TGF $\beta 1$ expression. However, the effects of miRs on TGF $\beta$ RI in CFs remain unknown.

In this study, we sought to investigate the potential relationship among hypoxia, miR-101a and TGF- $\beta$ signaling pathway in CFs. We found that hypoxia resulted in cardiac fibrosis by inducing the up-regulation of both TGF $\beta 1$ and its receptor, TGF $\beta$ RI, in CFs. Overexpression of miR-101a inhibited CF differentiation and the increased collagen content induced by hypoxia through the down-regulation of TGF $\beta R I$ and its downstream molecules; however, miR-101a had no effect on TGF $\beta 1$ expression. Furthermore, we confirmed TGF $\beta R I$ as a target of miR-101a. Our findings suggest that the anti-fibrotic effects of miR-101a are mediated by inhibiting TGF $\beta$ RI on CFs.

\section{Materials and Methods}

\section{Animal model and tissue preparation}

MI was induced in male Sprague-Dawley rats (weight 200-250 g) by ligation of the left anterior descending coronary artery (LAD) as previously described [22]. All experimental procedures were performed according to the guidelines of the Institutional Animal Care and Use Committee of Huazhong University of Science and Technology, PR China. Two weeks after the model was established, hearts were quickly isolated and prepared for HE, Masson staining and other experiments. 


\section{Cellular Physiology and Biochemistry}

Cell Physiol Biochem 2015;35:213-226

DOI: $10.1159 / 000369689$

Published onlıne: January 09, 2015

C) 2015 S. Karger AG, Basel

www.karger.com/cpb

HE, Masson staining and immunohistochemistry

The left ventricle was fixed in $4 \%$ paraformaldehyde, embedded with paraffin, and cut cross-sectionally into $5 \mu \mathrm{m}$-thick sections along the center of the fibrotic scar. HE staining was used to observe morphology. Masson trichrome staining was used to evaluate collagen deposition.

Tissue expression of TGF $\beta$ RI was assessed immunohistochemically using a polyclonal anti-TGF $\beta$ RI antibody (1:200, Santa Cruz, US). Briefly, tissue sections were de-waxed and washed in distilled water before an antigen retrieval step was performed to unmask the antigens. The sections were incubated with 3\% hydrogen peroxide (Sigma-Aldrich, US) for $15 \mathrm{~min}$ followed by 10\% goat serum for 30 min before being incubated overnight at $4^{\circ} \mathrm{C}$ with the primary antibody. The following day, the slides were washed with $1 \times$ PBS and treated with goat anti-rabbit antibody (1:200, Ant Gene, China) for $1 \mathrm{~h}$, followed by treatment with an avidin-biotin peroxidase complex for another hour. TGFR $\beta$ I expression was quantified using Image Pro Plus 6.0 for Integrated Optical Density (IOD) measurements.

\section{Cell culture and treatment}

The experiments used to culture CFs from neonatal Sprague-Dawley rats (1-3d) were performed as previously described [23]. Cells were plated in Dulbecco's Modified Eagle Medium (DMEM, Gibco, US) containing $10 \%$ fetal bovine serum (FBS, Gibco, US) and incubated at $37^{\circ} \mathrm{C}$ in $5 \% \mathrm{CO}_{2}$ with $95 \%$ air. The 2 nd or 3rd passages of CFs were used for following experiments. For hypoxia treatment, CFs were placed in a hypoxic chamber following starvation in serum-free medium for $24 \mathrm{~h}$ and maintained at $37^{\circ} \mathrm{C}$ in $93 \% \mathrm{~N}_{2}, 5 \%$ $\mathrm{CO}_{2}$ and $2 \% \mathrm{O}_{2}$ for $24 \mathrm{~h}$ as previously reported [24].

\section{Cell transfection procedure}

Cells were seeded in six-well plates and cultured for $24 \mathrm{~h}$ before transfection. For transfection, after incubation with $2 \mathrm{ml}$ serum-free medium for 4-6 h, the miRNAs (GenePharma, China) and lipofectamine 2000 (Invitrogen, US) were separately mixed with $500 \mu \mathrm{l}$ of Opti-MEM (Gibco, US) for $10 \mathrm{~min}$. The two mixtures were then combined and incubated for $20 \mathrm{~min}$. The lipofectamine-miRNA mixture was added to the cells, and the cells were incubated at $37^{\circ} \mathrm{C}$ for $6 \mathrm{~h}$. Subsequently, $2 \mathrm{ml}$ fresh DMEM medium was added to cells in each well for following experiments. miR-101a mimics (miR-101a) and its antisense oligonucleotides-miR-101a inhibitor (AMO-miR-101a) were synthesized by GenePharma (GenePharma, China). Additionally, a scrambled RNA was used as a negative control (NC). The sequences were as follows: miR-101a, sense: 5'-UACAGUACUGUGAUAACUGAA-3' and antisense: 5'-CAGUUAUCACAGUACUGUAUU-3'; AMO-miR-101a: 5'-UUCAGUUAUCACAGUACUGUA-3'; NC, sense: 5'-UUCUCCGAACGUGUCACGUTT-3' and antisense: 5'-ACGUGACACGUUCGGAGAATT-3'.

\section{Western blotting}

Total protein samples were extracted from heart tissues or CFs. Tissues or cells were lysed with lysis buffer (Beyotime, China). Then proteins $(40 \mu \mathrm{g})$ were fractionated on a $10 \%$ SDS-polyacrylamide gel, with GAPDH serving as an internal control. Primary antibodies and dilutions used were as follows: $\alpha$-SMA (1:2000, Gene Tex, US), TGFß1 (1:1000, Everest, UK), TGFßRI (1:500, Santa Cruz, US), c-Fos (1:500, Santa Cruz, US), p-Smad 3 (1:1000, Cell Signaling, US), Smad 3 (1:1000, Abcam, US) and GAPDH (1:1000, Ant Gene, China). Goat anti-rabbit antibody was used as a secondary antibody (1:2000, Ant Gene, China). Immunoreactivity was detected using a Bio-Rad Imaging System. The band intensity for each group was quantified using Image J software.

Quantitative reverse transcription-polymerase chain reaction ( $q R T-P C R$ )

Total RNA was extracted from heart tissues or CFs using Trizol (TAKARA, Japan) according to the manufacturer's protocol. The total RNA was then reverse transcribed into cDNA using a cDNA Reverse Transcription Kit (TAKARA, Japan). mRNA levels were quantified using a qRT-PCR mRNA SYBR Green Detection Kit (TAKARA, Japan) and calculated based on the $\Delta \Delta$ Ct comparative method, with GAPDH serving as an internal control. The primer sequences are shown in Table 1. The level of miR-101a was assessed using the qRT-PCR miRNA Detection Kit (GenePharma, China), with U6 serving as an internal control.

Immunofluorescence staining and confocal microscopy

After corresponding treatment, cultured CFs on glass cover slips were fixed with $4 \%$ paraformaldehyde for $15 \mathrm{~min}$. The samples were subsequently penetrated and blocked using blocking buffer $(1 \times \mathrm{PBS} / 5 \%$ 


\section{Cellular Physiology and Biochemistry}

Cell Physiol Biochem 2015;35:213-226

DOI: $10.1159 / 000369689$

Publisned online: January 09, 2015

Zhao et al.: MiRNA-101a Targets TGFßRI on CFs
(C) 2015 S. Karger AG, Basel

www.karger.com/cpb

Table 1. Primers for real time RT-PCR.

\begin{tabular}{|c|c|c|c|}
\hline Primer & Sense & Sequence & Product size \\
\hline \multirow[t]{2}{*}{ GAPDH } & Forward & 5'-GACATCAAGAAGGTGGTGAAGC-3' & $148 \mathrm{bp}$ \\
\hline & Reverse & 5'-TGTCATTGAGAGCAATGCCAGC-3' & \\
\hline \multirow[t]{2}{*}{ TGF $\beta 1$} & Forward & 5'-GCGCCTGCAGAGATTCAAGTCAAC-3' & $111 \mathrm{bp}$ \\
\hline & Reverse & 5'-GTATCAGTGGGGGTCAGCAGCC-3' & \\
\hline \multirow[t]{2}{*}{ TGF $\beta R I$} & Forward & 5'-GCTGGTCCAGTCTGCTTCG-3' & $258 \mathrm{bp}$ \\
\hline & Reverse & 5'-AAACCGACCTTTGCCGAT-3' & \\
\hline \multirow[t]{2}{*}{ Collagen I } & Forward & 5'-TTCACCTACAGCACGCTTGT-3' & $196 \mathrm{bp}$ \\
\hline & Reverse & 5'-TTGGGATGGAGGGAGTTTAC-3' & \\
\hline \multirow[t]{2}{*}{ Collagen III } & Forward & 5'-TGGCACAGCAGTCCAATGTAG-3' & $119 \mathrm{bp}$ \\
\hline & Reverse & 5'-GACAGATCCCGAGTCGCAGA-3' & \\
\hline \multirow[t]{2}{*}{ MMP 2} & Forward & 5'- GGGTCTCAGAACGCCGTGGAG-3' & $158 \mathrm{bp}$ \\
\hline & Reverse & 5'-ACAGGACGCAGAGAACCCGC-3' & \\
\hline \multirow[t]{2}{*}{ MMP 9} & Forward & 5'-GGGCATCTGGGGATTGAACTCAGC-3' & $147 \mathrm{bp}$ \\
\hline & Reverse & 5'-AGCGCCCGACGCACAGTAAG-3' & \\
\hline \multirow[t]{2}{*}{ c-Fos } & Forward & 5'-CAGCAGCAGCAACGAGCCCT-3' & $98 \mathrm{bp}$ \\
\hline & Reverse & 5'-CTCAGTCAGTGCCGGCTGCC-3' & \\
\hline
\end{tabular}

donkey serum $/ 0.3 \%$ Triton $^{\mathrm{TM}} \mathrm{X}-100$ ) for $1 \mathrm{~h}$ at room temperature. The cells were then incubated with an $\alpha$-SMA antibody (1:500, Gene Tex., US) overnight at $4^{\circ} \mathrm{C}$ before being incubated with a CY3-conjugated donkey anti-rabbit antibody (1:100, Ant Gene, China) for $2 \mathrm{~h}$. Cell nuclei were stained with DAPI (Beyotime, China) for $5 \mathrm{~min}$ at room temperature. Immunofluorescence was measured by a confocal microscopy (FV500, Olympus, Japan) to detect the expression of $\alpha$-SMA on CFs.

\section{Measurement of collagen content}

Total collagen content was quantitatively measured using a Sircol Collagen Assay (Biocolor, Northern Ireland) according to the manufacturer's protocol. Cultured cells were lysed with buffer and stirred at $4^{\circ} \mathrm{C}$ for $24 \mathrm{~h}$. Following centrifugation, supernatant for each sample $(100 \mu \mathrm{l})$ was obtained and stained with $1 \mathrm{ml}$ of Sircol Dye reagent, and the contents were subsequently mixed for $30 \mathrm{~min}$ at $4^{\circ} \mathrm{C}$. Following centrifugation, $1 \mathrm{ml}$ of Alkali reagent was added to each tube, and the samples were read at $540 \mathrm{~nm}$ (ELx 800, Bio-Tek, US). Collagen standard solutions were utilized to construct a standard curve, which was normalized to the total collagen content of each sample.

\section{Luciferase reporter assay}

To generate reporter vectors bearing miRNA-binding sites, we obtained fragments of the 3' UTRs of TGFßRI (rat) containing the exact target sites for miR-101a. Briefly, TGFßRI 3' UTRs were inserted into multiple cloning sites which are downstream of the luciferase gene (HindIII and SacI sites) in the pMIRReport (Promega, US). Then, $0.2 \mu \mathrm{g}$ of the chimeric plasmid (firefly luciferase vector), $0.05 \mu \mathrm{g}$ PRL-TK (TK-driven Renilla luciferase expression vector) and the appropriate miRNA plasmid $(0.6 \mu \mathrm{g})$ were cotransfected with lipofectamine 2000 (Invitrogen, US) into HEK-293 cells ( $4 \times 10^{5} /$ well) following $24 \mathrm{~h}$ of starvation in serum-free medium. Following transfection for $48 \mathrm{~h}$, luciferase activity was measured using a Dual-Glo ${ }^{\mathrm{TM}}$ Luciferase Reporter Assay Kit (Promega, US) on a luminometer (Olympus, Japan) according to the manufacturer's instructions.

\section{CF migration assay}

Transwell boyden chambers ( $8 \mu \mathrm{m}$ pore size, Corning, US) were used to determine the role of miR101a in CF migration. After corresponding treatments, CFs were harvested with $0.25 \%$ trypsin (Hyclone, US) and re-suspended ( $4 \times 10^{4}$ cells in $\left.100 \mu \mathrm{l}\right)$ with DMEM. Then $100 \mu \mathrm{l}$ of the cell suspension was loaded into the upper chambers of the migration apparatus, and DMEM containing 1\% FBS was added into the lower chambers as a chemotactic stimulus. Following incubation for $12 \mathrm{~h}$, migrated cells on the bottom side of the membrane were washed with $1 \times$ PBS, fixed with $4 \%$ paraformaldehyde, stained with crystal violet (Beyotime, China) and counted with a microscope (Olympus, Japan). Migration ability was quantified by counting the migrated cells in 5 random high power fields $(\times 200)$ for each membrane. 


\section{Cellular Physiology and Biochemistry}

Cell Physiol Biochem 2015;35:213-226

\begin{tabular}{l|l}
\hline DOI: $10.1159 / 000369689$ & (C) 2015 S. Karger AG, Basel
\end{tabular}

Zhao et al.: MiRNA-101a Targets TGFßRI on CFs

CF proliferation assay

An EdU Cell Proliferation Kit (Ribobio, China) was used to measure CF proliferation according to the manufacturer's instructions. Briefly, CFs $\left(1 \times 10^{4} /\right.$ well $)$ were seeded onto 96 -well culture plates and transfected with miRs following starvation for $24 \mathrm{~h}$ in serum-free DMEM. CFs were then subjected to hypoxia for $24 \mathrm{~h}$ including supplemented with EdU $(20 \mu \mathrm{M})$ for $2 \mathrm{~h}$. Following fixation with $4 \%$ paraformaldehyde and staining with Apollo $₫ 567$ and Hoechst 33342, photographs of the cells were taken using a fluorescent microscope (Olympus, Japan). Proliferation ratios of the CFs were quantified by counting stained cells in 5 random fields $(\times 200)$ for each group.

\section{Statistical analyses}

All data are presented as mean \pm SEM. One-way ANOVA, followed by Dunnett's test, was used for multiple comparisons. A two-tailed value of $P<0.05$ was considered statistically significant. Data were analyzed using Graph-Pad Prism 6.0 and SPSS 13.0.

\section{Results}

Down-regulation of miR-101a and up-regulation of TGF $\beta R I$ in infarcted hearts

We detected the expression of miR-101a in different regions of rat post-infarct hearts 2 weeks after LAD occlusion or sham operation. Masson staining demonstrated marked collagen deposition at the location of the infarct and at its border zone (Fig. 1A). The expression of miR-101a was decreased in post-infarct cardiac tissues, particularly in the infarct zone (Fig. 1B). Immunohistochemistry experiments involving the TGF $\beta R I$ showed a significant up-regulation of TGF $\beta R I$ in infarct zone and border zone compared with shamoperated animals (Fig. 1C-1D). Meanwhile, the mRNA expressions of TGF $\beta 1$, TGF $\beta$ RI, collagen I/III and MMP 2/9 were up-regulated in infarct zone and border zone compared with shamoperated animals (Fig. 1E-1J). However, in the remote zone, only collagen I/III mRNA levels were increased with statistical difference in comparison to sham group. Western blot results showed higher protein levels of TGF $\beta 1$, TGF $\beta$ RI and $\alpha$-SMA in the infarct and border zone compared with sham group (Fig. $1 \mathrm{~K}-1 \mathrm{~N}$ ). The expression of TGFßRI was higher in the remote zone of MI group than in the sham model, but did not reach statistical significance.

Hypoxia induces fibrosis in CFs but attenuates the expression of miR-101 a of CFs in vitro

To examine the fibrotic effects of hypoxia on CFs, we used neonatal rat CFs to detect the expression of TGF- $\beta$ signaling axis and miR-101a in vitro. We found that hypoxia $(2 \%$ $\mathrm{O}_{2}, 24 \mathrm{~h}$ ) resulted in a significant increase in TGF $\beta 1$, TGF $\beta R I$, MMP 2/9 and collagen I/III mRNA levels in CFs (Fig. 2A). However, the expression of miR-101a in CFs was reduced by approximately $30 \%$ in response to hypoxia (Fig. 2B). Western blot results illustrated that the protein expression levels of TGF $\beta 1$, TGF $\beta R I$, p-Smad 3 and $\alpha$-SMA were significantly up-regulated in response to hypoxia (Fig. 2C-2F). Taken together, these data indicate that prolonged hypoxia actives the TGF- $\beta$ signaling pathway by enhancing the expression of both TGF $\beta 1$ and TGF $\beta R I$, inducing CF differentiation and increasing CF collagen expression. Whether a potential correlation exists between the hypoxia-induced down-regulation of miR-101a and the up-regulation of the TGF $\beta$-TGF $\beta$ RI-Smad axis remains unknown.

\section{Delivery of miR-101a inhibits hypoxia-induced TGF $\beta R I$ expression, CF differentiation and} fibrosis

The mRNA expression levels of collagen I/III and MMP 2/9 in CFs exhibited an evident decline when the cells were treated with miR-101a ( $50 \mathrm{nM})$ in the setting of hypoxia, and this decrease was abolished by co-treatment with AMO-miR-101a (100 nM) (Fig. 3A-3E). Delivery of miR-101a into CFs had no effect on TGF 31 expression in CFs (Fig. 3F-3G). However, CFs transfected with miR-101a were characterized by diminished expression of TGFßRI (Fig. $3 \mathrm{H}-3 \mathrm{I}$ ) and the downstream signaling molecule, p-Smad 3 (Fig. 4A), compared with CFs cotransfected with AMO-miR-101a or transfected with NC alone (100 nM). The expression of 


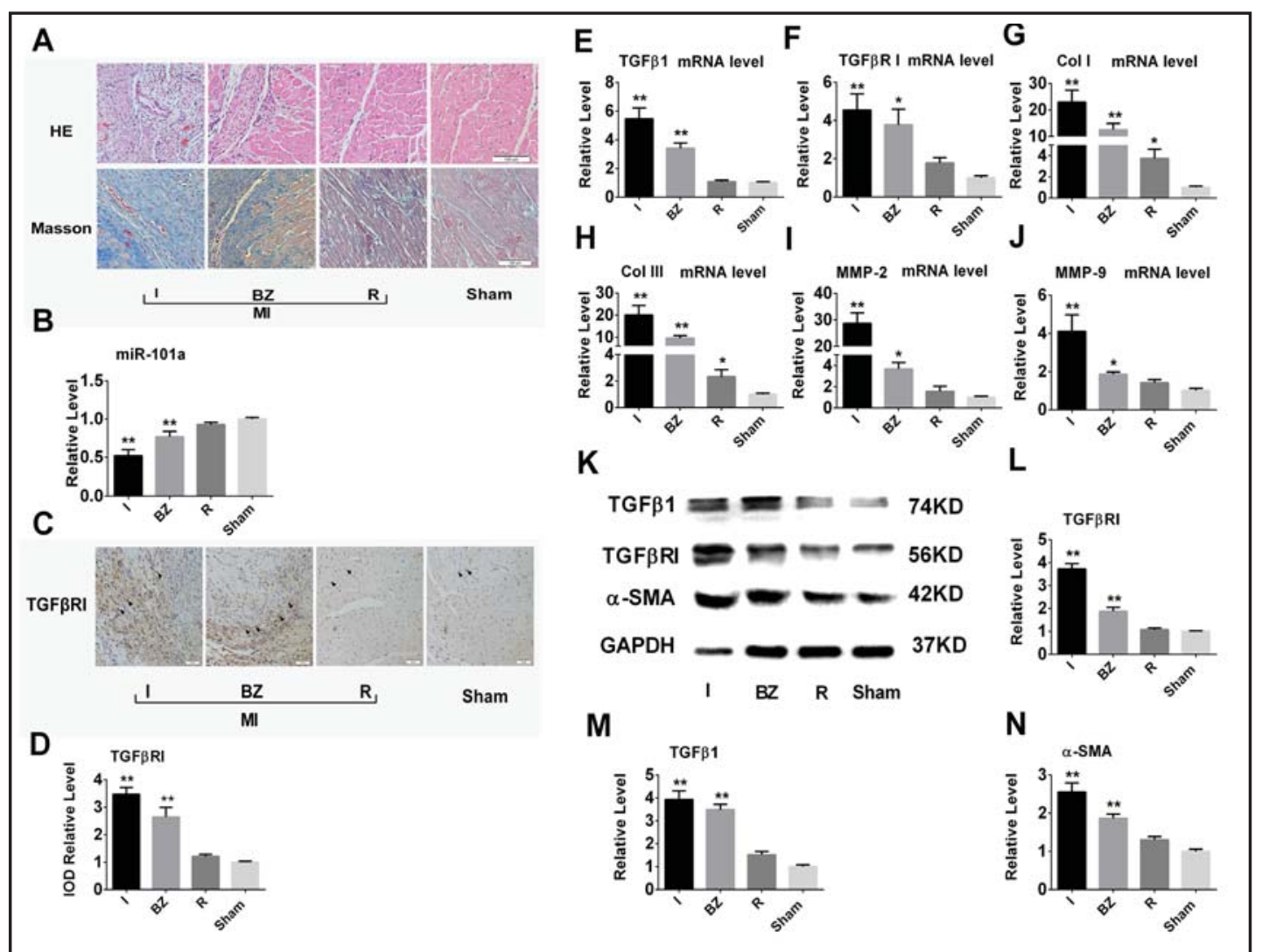

Fig. 1. Down-regulation of microRNA-101a (miR-101a) and up-regulation of transforming growth factor $\beta$ receptor I (TGFßRI) expression following myocardial infarction (MI). (A) HE and Masson trichrome staining of rat heart sections demonstrated interstitial fibrosis in the infracted myocardium with collagen deposition 2 weeks after MI $(10 \times 20$ magnification of $200 \times)(n=5)$. (B) Compared with sham-operated hearts, miR-101a expression was markedly decreased in the infarct zone and border zone $(n=6)$. (C-D) Immunohistochemical staining demonstrated a significant increase in TGF $\beta$ RI expression in the infarct zone and border zone $(10 \times 40$ magnification of $400 \times)(n=6)$. (E-J) Compared with sham-operated hearts, mRNA levels of transforming growth factor $\beta 1$ (TGF $\beta 1$ ), TGF $\beta$ RI, collagen I/III (Col I/III) and matrix metalloproteinase 2/9 (MMP 2/9) were increased in the infarct zone and border zone $(n=6) .(K-N)$ The protein expression levels of TGF $\beta 1$, TGF $\beta$ RI and $\alpha$-smooth muscle actin ( $\alpha$-SMA) were up-regulated in the infarct zone and border zone $(n=6)$. I: infarct zone; BZ: border zone; R: remote zone; IOD: integrated optical density; Data are shown as mean \pm SEM. ${ }^{*} P<0.05,{ }^{* *} P<0.01$ vs. sham. Arrows denote a TGF $\beta$ RI-positive region in CFs.

$\alpha$-SMA also markedly decreased following treatment with miR-101a, indicating that miR101a exerted significant anti-differentiation effects on CFs (Fig. 4B-4C). Moreover, collagen content detection demonstrated that the delivery of miR-101a inhibited the hypoxiainduced up-regulation of CF collagen content (Fig. 4D). These data strongly suggest that under hypoxic conditions, the anti-fibrotic effects of miR-101a on CFs may be mediated by inhibiting the TGF $\beta R I-S m a d$ signaling axis.

\section{TGFBRI is one of the targets of miR-101a}

To eliminate the influence of potential confounding factors of hypoxia, we scrutinized the expression of TGF $\beta R I$ at the mRNA and protein levels via the transfection of miR-101a in the absence of hypoxia. Western blot and real-time PCR results revealed that, despite being cultured under normoxic conditions, CFs treated with miR-101a exhibited a significant down-regulation of TGF $\beta R I$. However, AMO-miR-101a dramatically increased the expression of TGF $\beta$ RI, and abrogated the effect of miR-101a on TGFßRI (Fig. 5A-5B). 


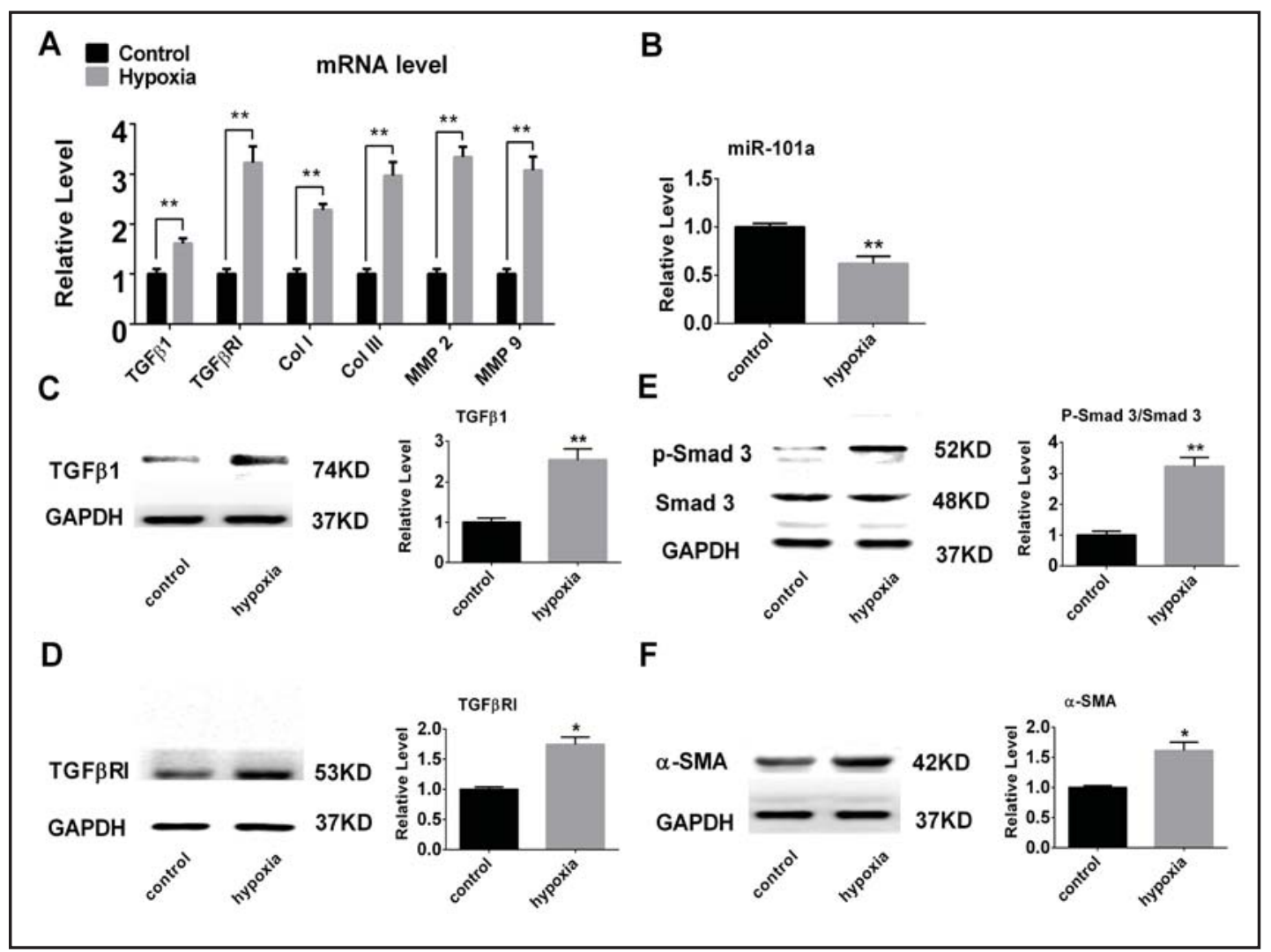

Fig. 2. Hypoxia induces fibrosis but decreases the expression of miR-101a in CFs. (A-B) Hypoxia increased the mRNA levels of TGF $\beta 1$, TGF $\beta$ RI, Col I/III and MMP 2/9 but suppressed miR-101a in CFs. (C-F) Hypoxia up-regulated the protein expression levels of TGF $\beta 1$, TGF $\beta$ RI, phosphorylated drosophila mothers against decapentaplegic protein 3 (p-Smad 3) and $\alpha$-SMA. Data are shown as mean \pm SEM; $n=3$ to 5 . ${ }^{*} P<0.05$, ${ }^{* *} P<0.01$ vs. control (no treatment).

Computational predictions revealed that the seed sites of miR-101a matched with the TGFßRI 3' UTR, suggesting that TGFßRI may be a target of miR-101a (Fig. 5C). To further elucidate whether miR-101a interferes with TGF $\beta$ RI's 3' UTR, we utilized the pMIR-Report to construct plasmids containing TGFßRI binding sites for miR-101a sequences in HEK293 cells. Luciferase reporter assays were divided into three parts. Firstly, there was no difference of luciferase activity between the plasmid without TGFßRI 3' UTR + the plasmid with miR-101a negative control (3' UTR-NC + miRNA-NC) and plasmid without TGFßRI 3' UTR + plasmid with miR-101a ( $3^{\prime}$ UTR-NC + miRNA) ( $\left.p=0.877\right)$, implying that miR-101a did not combine with empty TGFßRI vector. Additionally, the luciferase vector carrying the $3^{\prime}$ UTR of TGFßRI was co-transfected with miR-101a ( $3^{\prime}$ UTR + miRNA), and luciferase activity was robustly diminished compared with the control (3' UTR + miRNA-NC) $(p=0.009)$. This result indicates that the TGF $\beta$ RI 3' UTR could combine with miR-101a. Finally, there was also no significant difference in luciferase activity between plasmid containing a mutation of the TGFßRI 3' UTR + miR-101a negative control (3' UTR-MU + miRNA-NC) and the plasmid containing a mutation of the TGF $\beta$ RI 3' UTR + miR-101a (3' UTR-MU + miRNA) $(p=0.129)$, which demonstrated that miR-101a could not combine with the mutated TGF $\beta R I$ 3' UTR. Moreover, mutation of the miRNA-101a seed region within the TGF $\beta$ RI 3' UTR (3' UTR-MU + miRNA) abrogated the repressive ability of the miRNA-101a (3' UTR + miRNA) $(p=0.003)$, demonstrating specificity of the target sequence for TGF $\beta$ RI (Fig. 5D-5E). All of these results confirm TGF $\beta R I$ as one of the targets of miR-101a. 


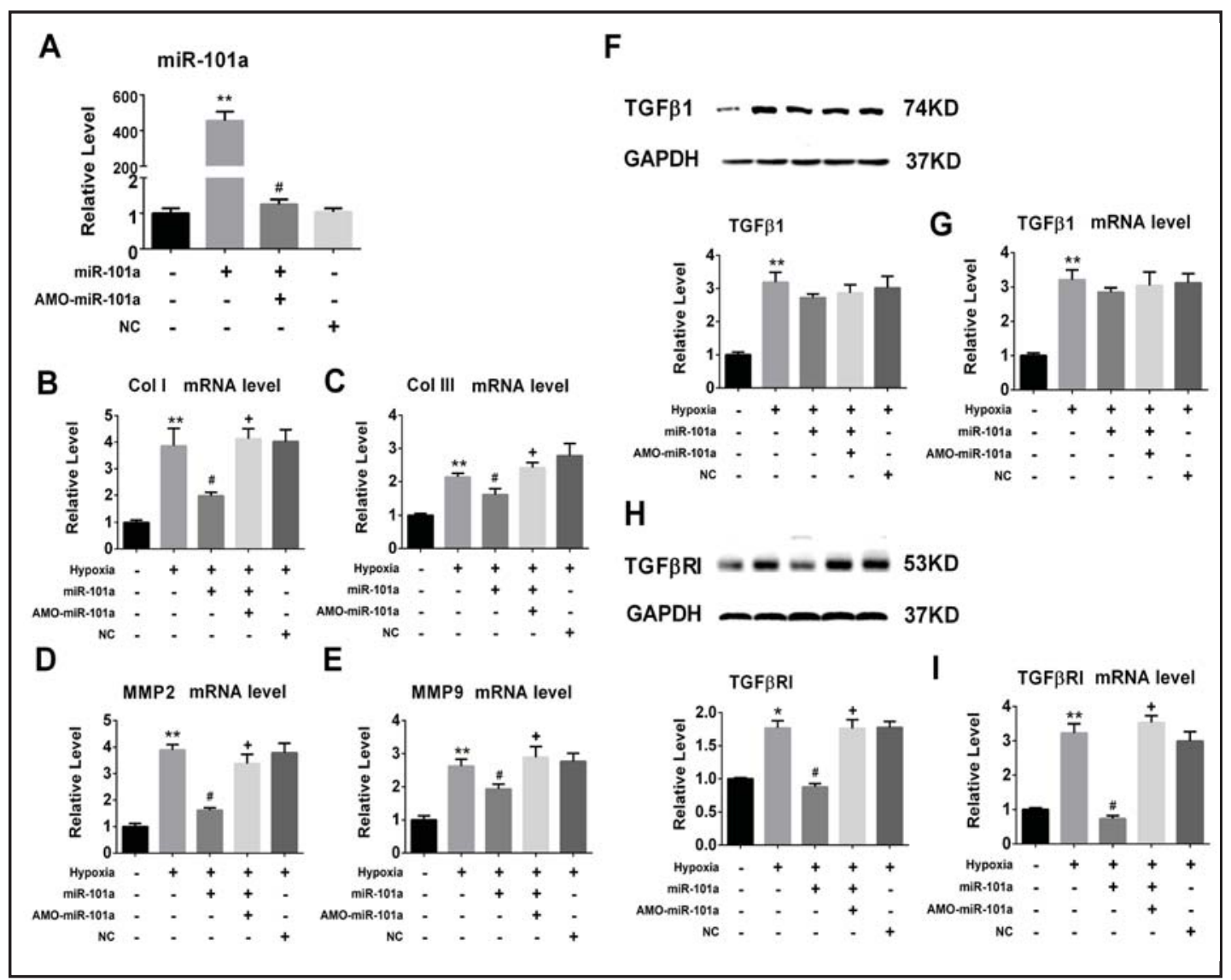

Fig. 3. The anti-fibrotic effects of miR-101a on CFs. (A) miR-101a levels increased significantly when CFs were transfected with miR-101a. Data are shown as mean \pm SEM; $n=3$ to 5 . ${ }^{*} P<0.05$, ${ }^{* *} P<0.01$ vs. control (no treatment); \#P<0.05 vs. miR-101a. (B-E) Delivery of miR-101a inhibited the mRNA expression of Col I/III and MMP 2/9 in CFs. (F-G) Delivery of miR-101a had no effect on TGFß1 in CFs. (H-I) Delivery of miR-101a decreased protein and mRNA levels of TGF $\beta$ RI in CFs. Data are shown as mean \pm SEM; $n=3$ to 5 . ${ }^{*} P<0.05$, ** $P<0.01$ vs. control (no treatment); $\# P<0.05$ vs. hypoxia; $+P<0.05$ vs. hypoxia+miR-101a. miR-101a: miR101a mimics; AMO-miR-101a: miR-101a inhibitor; NC: negative control.

Over-expression of miR-101 a reverses the hypoxia-induced enhancements of CF migration ability and further reduces the proliferation of $C F$

We investigated whether hypoxia regulated the migration ability of CFs using transwell inserts. Upon stimulation with 1\% FBS, CFs treated with hypoxia exhibited apparent enhancements of migration activity. When treated with miR-101a, this improved migration activity was significantly retarded. However, this inhibitory effect was greatly offset when CFs were co-transfected with AMO-miR-101a, indicating that miR-101a reversed the migration enhancements induced by hypoxia (Fig. 6A-6B).

Using an EdU proliferation assay, we detected changes in CF proliferation ratios in the setting of hypoxia. We found that hypoxia resulted in a 30\% decrease in CF proliferation rates. Moreover, the delivery of miR-101a further reduced the proliferation rates compared to treatment with hypoxia alone, indicating that miR-101a may inhibit CF proliferation (Fig. 6C-6D). We further examined the expression of c-Fos, a gene involved in proliferation, under hypoxic conditions. It demonstrated that hypoxia inhibited the expression of c-Fos in CFs and that the delivery of miR-101a further enhanced this inhibitory effect (Fig. 6E-6F). Our findings are consistent with those of a previous study that miR-101a inhibits CF proliferation by targeting c-Fos [22]. These results indicate that hypoxia is not an inducer of c-Fos in CFs, and miR-101a inhibits CF proliferation by inhibiting the expression of c-Fos. 


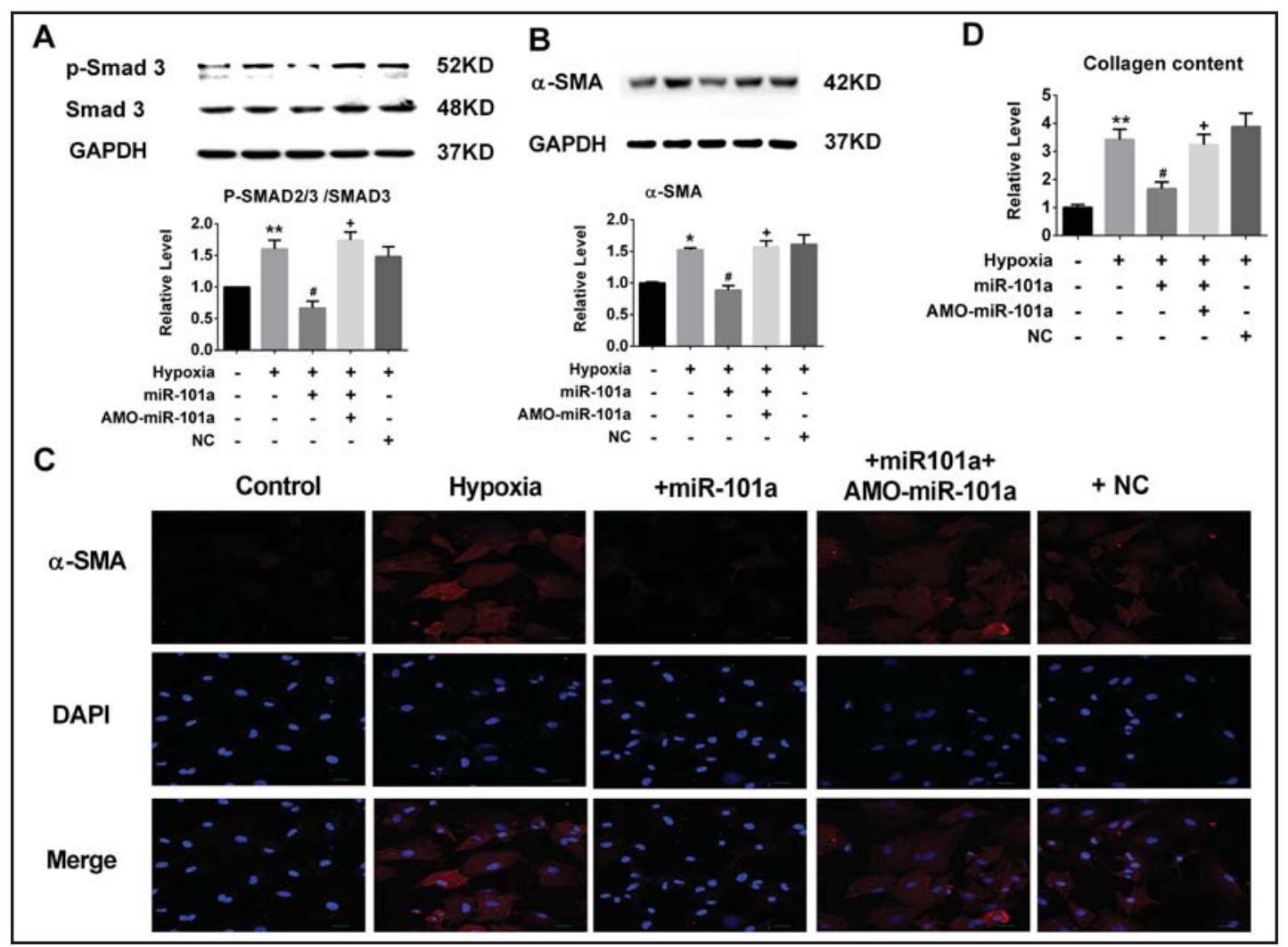

Fig. 4. Delivery of miR-101a inhibits CF differentiation and reduces CF collagen content. (A) Delivery of miR-101a inhibited the expression of p-Smad 3 but not Smad 3. (B) Delivery of miR-101a effectively inhibited the expression of $\alpha$-SMA in CFs. (C) Fluorescence-labeled $\alpha$-SMA protein was visualized by fluorescence confocal microscopy to detect CF differentiation (bars: $50 \mu \mathrm{m}$ ). (D) Delivery of miR-101a reduced the collagen content of CFs. Data are shown as mean \pm SEM; $n=3$ to $5 .{ }^{*} P<0.05,{ }^{* *} P<0.01$ vs. control (no treatment); $\# P<0.05$ vs. hypoxia; $+P<0.05$ vs. hypoxia+miR-101a. miR-101a: miR-101a mimics; AMO-miR-101a: miR101a inhibitor; NC: negative control.

\section{Discussion}

In the present study, we observed a negative correlation between the up-regulation of the TGF- $\beta$ signaling pathway and the down-regulation of miR-101a in post-infarct rat hearts and cultured CFs treated with hypoxia. We found that miR-101a suppressed the CF differentiation, migration and collagen production by inhibiting the expression of TGF $\beta$ RI and downstream molecules. Moreover, our data verified that miR-101a exerted these antifibrotic effects on CFs via directly targeting TGF $\beta$ RI to inhibit the TGF- $\beta$ signaling pathway.

Cardiac fibrosis is a basic pathological characteristic of post-infarct myocardium [25] and plays a pivotal role in the development of other cardiovascular diseases such as heart failure and atrial fibrillation $[26,27]$. It is well established that TGF- $\beta$ pathway plays an important role in the progression of cardiac fibrosis [7]. Previous studies demonstrated an up-regulation of TGF $\beta$ RI for at least 2 months after MI in rats, which was correlated with left ventricular remodeling [28]. We consistently observed that TGF 1 and TGFßRI expression levels were significantly increased in areas of collagen deposition 2 weeks following LAD occlusion in the rat MI model. We also found that hypoxia up-regulated the expression levels of TGF $\beta 1$ and TGF $\beta R I$, increased CF collagen content and migration ability, and induced CF differentiation in vitro. These results indicate that hypoxia induces cardiac fibrosis via upregulating the TGF $\beta$-TGF $\beta$ R-Smad axis, suggesting that hypoxia may be at the heart of postinfarct cardiac remodeling and function as a key mediator in the development of cardiac fibrosis. 
Fig. 5. Experimental establishment of TGF $\beta R I$ as a target of miR101a. (A-B) Delivery of miR-101a significantly decreased the protein and mRNA expression of TGFßRI in CFs. Data are shown as mean \pm SEM; $\mathrm{n}=3$ to $5 .{ }^{*} P<0.05$, ${ }^{* *} P<0.01$ vs. control (no treatment); $\# P<0.05$ vs. miR-101a. miR-101a: miR-101a mimics; AMO-miR-101a: miR101a inhibitor; NC: negative control. (C) The sequences illustrating the binding sites of miR-101a: mRNA is complementary between miR-101a and TGF $\beta R I$ for rat, mouse and human genes, respectively. The matched base pairs are marked with dashed red rectangles. (D-E) Analysis of luciferase activity in HEK293T cells transfected with plasmids

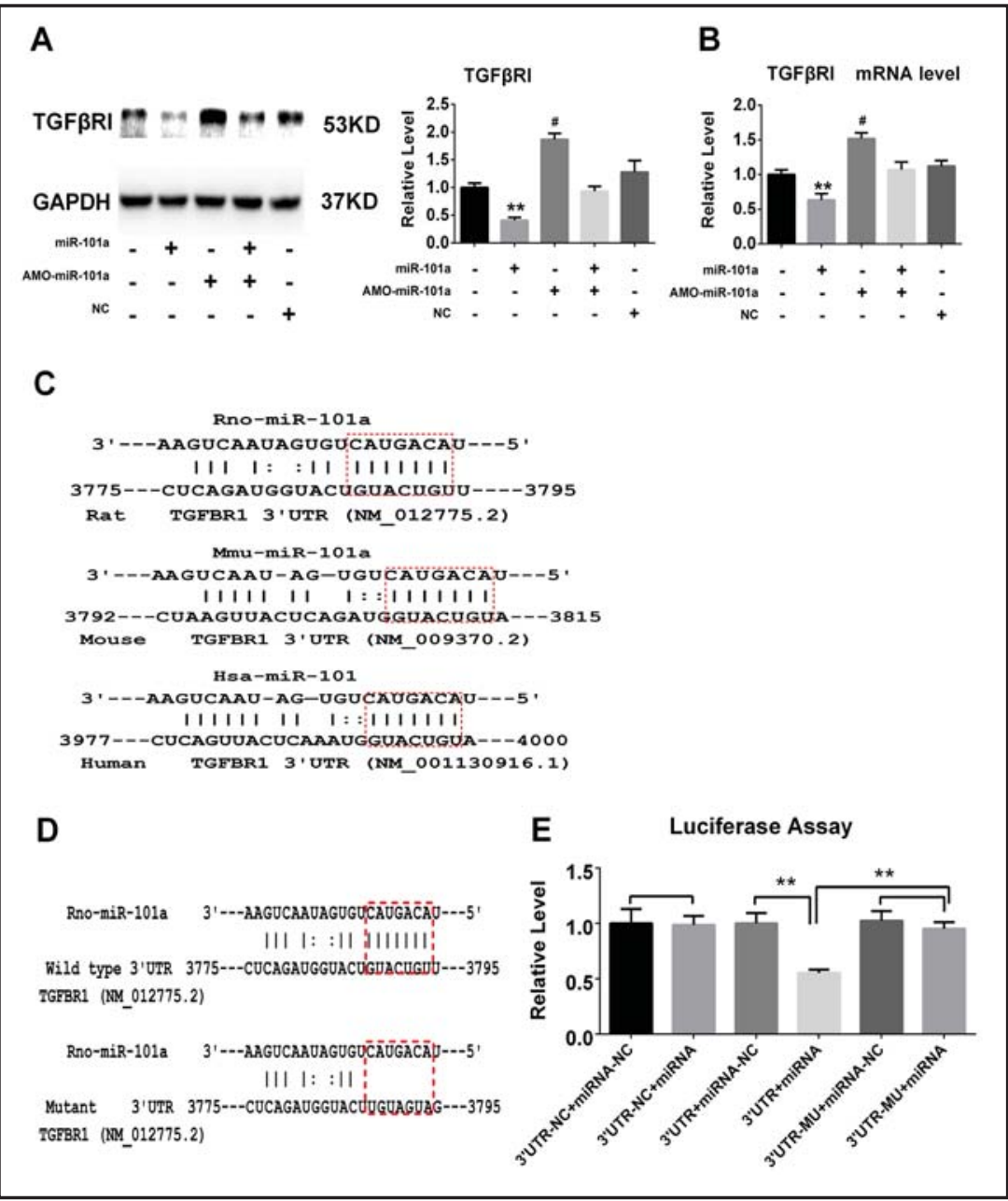
containing miR-101a or the TGFßRI 3' untranslated region (3' UTR) sequences. Data are shown as mean \pm $\mathrm{SEM} ; \mathrm{n}=6{ }^{*} P<0.05,{ }^{* *} P<0.01$. $3^{\prime}$ UTR -NC: plasmid with an empty vector; $3^{\prime}$ UTR: plasmid with the TGF $\beta$ RI 3' UTR; 3' UTR -MU: plasmid with mutation of the TGFßRI 3' UTR; miRNA: plasmid with miR-101a; miRNA-NC: plasmid with miR-101a negative control.

Various cardiovascular diseases, including dilated cardiomyopathy [29], aortic stenosis [29] and ischemic heart disease [30], are characterized by reduced levels of cardiac miR-101. A previous study [31] demonstrated that low levels of circulating miR-101 may be predictive of a higher risk of impaired left ventricular contractility and left ventricular remodeling in post-infarct patients. Additionally, another study [32] reported that miR-101 was detected in patients without cardiac remodeling but was totally absent in patients with remodeling. These data suggested that the circulating miR-101 was negatively correlated with postinfarct remodeling. Yang B et al. [22] reported that miR-101a levels were decreased in postinfarct heart tissue and that miR-101a was more abundant in CFs than in cardiomyocytes, which also demonstrated that the down-regulation of miR-101a was negatively associated with post-infract cardiac fibrosis. In this study, we consistently found that the expression of miR-101a was down-regulated in post-infarct rat hearts and cultured neonatal CFs treated with hypoxia. In contrast, a recent study [33] demonstrated that miR-101 was increased in human umbilical vein endothelial cells (HUVECs) exposed to hypoxic conditions and stimulated angiogenesis as a means of improving post-ischemic vascular remodeling in mouse ischemic hind limbs. These results suggest that hypoxia-induced expression of miR101 may depend on the cell type involved. 


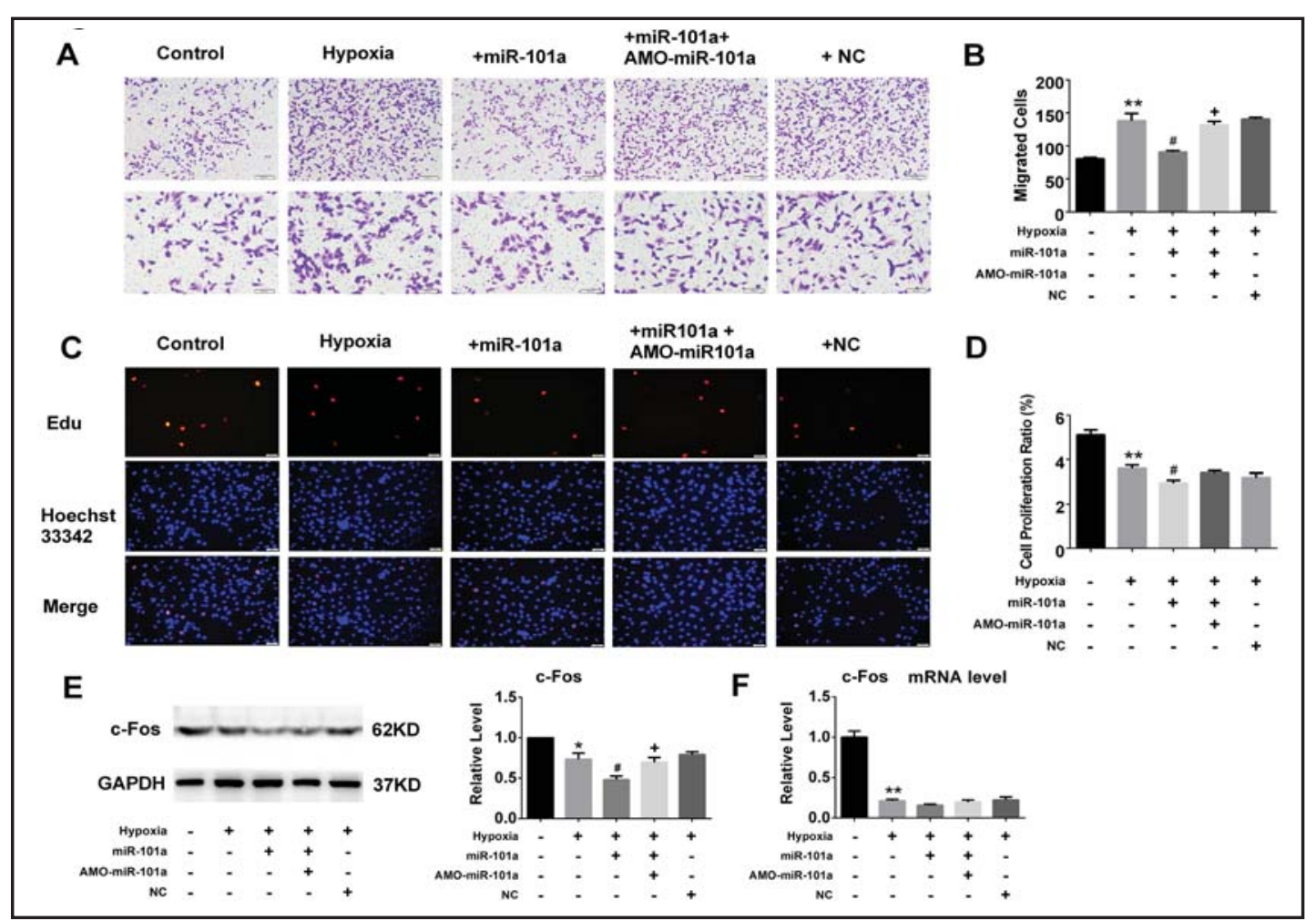

Fig. 6. The role of miR-101a in CF migration and proliferation in the setting of hypoxia. (A-B) Effect of miR101a on the migration of cultured CFs was determined by a transwell migration assay (upper panel: $10 \times 10$ magnification of $100 \times$; lower panel: $10 \times 20$ magnification of $200 \times$ ). (C-D) The effect of miR-101a on the proliferation of cultured CFs was determined by an EdU proliferation assay. The proliferating cells were visualized as red, and the nuclei, as blue (10×40 magnification of 400×). (E-F) Hypoxia suppressed the protein and mRNA expression of c-Fos in CFs, which was further reduced by miR-101a. Data are shown as mean \pm SEM; $\mathrm{n}=3$ to $5 .{ }^{*} P<0.05$, ${ }^{* *} P<0.01$ vs. control (no treatment); $\# P<0.05 v s$. hypoxia; $+P<0.05$ vs. hypoxia+miR-101a. miR-101a: miR-101a mimics; AMO-miR-101a: miR-101a inhibitor; NC: negative control.

Tissue specificity is the property of miRs expression that determines the contributions of certain miRs to biological and pathological processes of tissues or organs [13, 34]. A growing number of miRNAs (e.g., miR-133 [35], miR-101 [22], miR-24 [21], miR-590 [35], miR-29 [20]) have been shown to affect the biological functions of CFs by inhibiting TGF- $\beta$ signaling and exerting subsequent anti-fibrotic effects. To be specific, miR-24 [21] and miR133 [35] have been shown to alleviate fibrosis by suppressing TGF $\beta 1$, whereas miR-590 [35] exerts anti-fibrotic effects by targeting TGF $\beta$ RII, and miR-29 [20] is confirmed to inhibit CF differentiation by directly inhibiting Smad 3. A recent study [22] demonstrated that miR101a inhibited post-infarct cardiac fibrosis and improved left ventricular compliance via the c-Fos/TGF- $\beta 1$ pathway.

Previous study [22] demonstrated that delivery of miR-101a into CFs could suppress the up-regulation of TGF $\beta 1$ induced by Angiotensin II (Ang II). Our results demonstrated that over-expression of miR-101a suppressed hypoxia-induced CF differentiation, migration and collagen production. However, the anti-fibrotic effects of miR-101a were mediated via the inhibition of TGF $\beta$ RI and downstream signaling molecule p-Smad 3, but not TGF $\beta 1$, indicating a different anti-fibrotic mechanism in the setting of hypoxia and that miR-101a may directly inhibit the expression of TGF $\beta R I$. Luciferase reporter assays, western blot and real time PCR results verified that TGF $\beta$ RI was a target of miR-101a. Taken together, our results suggest that the anti-fibrotic effects exerted by miR-101a on CFs in the setting of hypoxia are independent of its inhibition on TGF $\beta 1$, which has already been proven [22]. miRNAs usually have multiple targets, and may exert similar functions in different organs. 


\section{Cellular Physiology and Biochemistry}

Cell Physiol Biochem 2015;35:213-226

\begin{tabular}{l|l}
\hline DOI: $10.1159 / 000369689$ & (C) 2015 S. Karger AG, Basel
\end{tabular}

www.karger.com/cpb

Zhao et al.: MiRNA-101a Targets TGF $\beta$ RI on CFs

When organizing this manuscript, we found a newly published study [36] reporting that miR101a suppressed the TGF- $\beta$ signaling pathway by targeting TGF $\beta$ RI and its transcriptional activator, Kruppel-like factor 6 (KLF 6), during liver fibrogenesis. Our results consistently demonstrated that TGF $\beta R I$ is a target gene of miR-101a. These results also suggest that miR101a is another important anti-fibrotic miRNA in the heart, in addition to the established ones (e.g., miR-29 [20, 30], miR-590 [35] and miR-30c [37]).

Myofibroblasts are highly active cells that express $\alpha$-SMA and exhibit improved proliferation, migration and collagen protein secretion [38]. The phenotypic transformation of CFs into myofibroblasts is a key event in myocardial injury and cardiac remodeling processes $[39,40]$. During the repair phase in post-infarct myocardium, CFs undergo phenotypic transformation to become myofibroblasts, which is a critical step in the repair process following myocardial injury. However, myofibroblasts may persist for months or even years, which may precipitate cardiac fibrosis and result in myocardial stiffness and impaired cardiac function [41]. It is well accepted that TGF $\beta 1$ and its downstream signaling molecules play a pivotal role in CF differentiation, therefore, TGF- $\beta$ signaling pathway should be considered a pivotal target in cardiac fibrosis [7, 42].

In this study, the increased collagen content and enhanced migration abilities of CFs correlated positively with the hypoxia-induced up-regulation of $\alpha$-SMA, suggesting that these fibrotic effects may be due to the transformation of CFs into myofibroblasts. miR-101a significantly inhibited the hypoxia-induced enhancement of migration activity in CFs, which implied that miR-101a reduced CF migration ability by inhibiting differentiation. However, we found that prolonged hypoxia did not improve CF proliferation ratios, which strongly implied that the fibrotic effects of hypoxia were the result of CF differentiation rather than proliferation. These results suggested that the core of anti-fibrotic effects of miR-101a was mediated by blocking TGF- $\beta$ pathways to inhibit CF differentiation as opposed to the cell's proliferation.

Although the importance of TGF- $\beta$ signaling pathway in post-infarct cardiac fibrosis has been well established, studies concerning TGFßRI on cardiac fibrosis remain limited. Animal experiments $[12,43]$ have shown that application of a TGFßRI inhibitor results in significant attenuation of post-infarct remodeling and improvements in rat cardiac function. A very recently published study [44] demonstrated that the application of a TGFßRI inhibitor (SD 208) even reversed CF differentiation under 3D culture condition. Therefore, inhibiting the TGF- $\beta$ signaling pathway by suppressing the expression of TGF $\beta$ RI may be a promising method to block the differentiation of CFs and prevent cardiac fibrosis. In the present study, we consistently observed that miR-101a suppressed CF differentiation and fibrosis by targeting TGF $\beta R I$. Meanwhile, increasing miRs $[22,36,45,46]$ were found to be able to extenuate organ fibrosis by inhibiting the expression of TGF $\beta$ RI, for example, let-7 [45] had been confirmed to inhibited renal fibrosis by targeting TGF $\beta$ RI on renal cells.

In summary, our study illustrates that the anti-fibrotic miRNA, miR-101a, inhibits TGF- $\beta$ signaling pathway to exert its anti-fibrotic effects via targeting TGF $\beta R I$, which is independent of TGF- $\beta 1$. This study further indicates the multi-faceted role of miR-101a in blocking the TGF- $\beta$ signaling axis, which mediates myocardial fibrosis. miR-101a may be an attractive therapeutic target for the amelioration of post-infarct cardiac fibrosis and the improvement of cardiac function.

\section{Acknowledgments}

This work was supported by Natural Science Foundation of China (30971242).

\section{Disclosure Statement}

None declared. 


\section{Cellular Physiology and Biochemistry}

Cell Physiol Biochem 2015;35:213-226

\begin{tabular}{l|l}
\hline DOI: $10.1159 / 000369689$ & (C) 2015 S. Karger AG, Basel
\end{tabular}

Zhao et al.: MiRNA-101a Targets TGFßRI on CFs

\section{References}

1 Porter KE, Turner NA: Cardiac fibroblasts: at the heart of myocardial remodeling. Pharmacol Ther 2009;123:255-278.

2 Tan AY, Zimetbaum P: Atrial fibrillation and atrial fibrosis. J Cardiovasc Pharmacol 2011;57:625-629.

-3 Lajiness JD, Conway SJ: Origin, development, and differentiation of cardiac fibroblasts. J Mol Cell Cardiol 2013

4 van den Borne SW, Diez J, Blankesteijn WM, Verjans J, Hofstra L, Narula J: Myocardial remodeling after infarction: the role of myofibroblasts. Nat Rev Cardiol 2010;7:30-37.

-5 Barallobre-Barreiro J, Didangelos A, Schoendube FA, Drozdov I, Yin X, Fernandez-Caggiano M, Willeit P, Puntmann VO, Aldama-Lopez G, Shah AM, Domenech N, Mayr M: Proteomics analysis of cardiac extracellular matrix remodeling in a porcine model of ischemia/reperfusion injury. Circulation 2012;125:789-802.

-6 Watson CJ, Collier P, Tea I, Neary R, Watson JA, Robinson C, Phelan D, Ledwidge MT, McDonald KM, McCann A, Sharaf O, Baugh JA: Hypoxia-induced epigenetic modifications are associated with cardiac tissue fibrosis and the development of a myofibroblast-like phenotype. Hum Mol Genet 2014;23:2176-2188.

7 Blobe GC, Schiemann WP, Lodish HF: Role of transforming growth factor beta in human disease. N Engl J Med 2000;342:1350-1358.

8 Derynck R, Zhang YE: Smad-dependent and smad-independent pathways in tgf-beta family signalling. Nature 2003;425:577-584.

-9 Itoh S, Ten DP: Negative regulation of tgf-beta receptor/smad signal transduction. Curr Opin Cell Biol 2007;19:176-184.

10 Petersen M, Thorikay M, Deckers M, van Dinther M, Grygielko ET, Gellibert F, de Gouville AC, Huet S, Ten DP, Laping NJ: Oral administration of gw788388, an inhibitor of tgf-beta type i and ii receptor kinases, decreases renal fibrosis. Kidney Int 2008;73:705-715.

11 Rojas A, Padidam M, Cress D, Grady WM: Tgf-beta receptor levels regulate the specificity of signaling pathway activation and biological effects of tgf-beta. Biochim Biophys Acta 2009;1793:1165-1173.

12 Tan SM, Zhang Y, Connelly KA, Gilbert RE, Kelly DJ: Targeted inhibition of activin receptor-like kinase 5 signaling attenuates cardiac dysfunction following myocardial infarction. Am J Physiol Heart Circ Physiol 2010;298:H1415-H1425.

13 van Rooij E: The art of microrna research. Circ Res 2011;108:219-234.

14 Yang B, Lin H, Xiao J, Lu Y, Luo X, Li B, Zhang Y, Xu C, Bai Y, Wang H, Chen G, Wang Z: The muscle-specific microrna mir-1 regulates cardiac arrhythmogenic potential by targeting gja1 and kcnj2. Nat Med 2007;13:486-491.

-15 Care A, Catalucci D, Felicetti F, Bonci D, Addario A, Gallo P, Bang ML, Segnalini P, Gu Y, Dalton ND, Elia L, Latronico MV, Hoydal M, Autore C, Russo MA, Dorn GN, Ellingsen O, Ruiz-Lozano P, Peterson KL, Croce CM, Peschle C, Condorelli G: Microrna-133 controls cardiac hypertrophy. Nat Med 2007;13:613-618.

-16 van Rooij E, Sutherland LB, Qi X, Richardson JA, Hill J, Olson EN: Control of stress-dependent cardiac growth and gene expression by a microrna. Science 2007;316:575-579.

17 Sayed D, Hong C, Chen IY, Lypowy J, Abdellatif M: Micrornas play an essential role in the development of cardiac hypertrophy. Circ Res 2007;100:416-424.

$\checkmark 18$ Thum T, Catalucci D, Bauersachs J: Micrornas: novel regulators in cardiac development and disease. Cardiovasc Res 2008;79:562-570.

19 Liang H, Zhang C, Ban T, Liu Y, Mei L, Piao X, Zhao D, Lu Y, Chu W, Yang B: A novel reciprocal loop between microrna-21 and tgfbetariii is involved in cardiac fibrosis. Int J Biochem Cell Biol 2012;44:2152-2160.

20 Zhang Y, Ru HX, Wei LH, Chung AC, Yu CM, Lan HY: Mir-29b as a therapeutic agent for angiotensin iiinduced cardiac fibrosis by targeting tgf-beta/smad3 signaling. Mol Ther 2014;22:974-985.

21 Wang J, Huang W, Xu R, Nie Y, Cao X, Meng J, Xu X, Hu S, Zheng Z: Microrna-24 regulates cardiac fibrosis after myocardial infarction. J Cell Mol Med 2012;16:2150-2160.

22 Pan Z, Sun X, Shan H, Wang N, Wang J, Ren J, Feng S, Xie L, Lu C, Yuan Y, Zhang Y, Wang Y, Lu Y, Yang B: Microrna-101 inhibited postinfarct cardiac fibrosis and improved left ventricular compliance via the fbj osteosarcoma oncogene/transforming growth factor-beta1 pathway. Circulation 2012;126:840-850.

-23 Mitchell MD, Laird RE, Brown RD, Long CS: Il-1beta stimulates rat cardiac fibroblast migration via map kinase pathways. Am J Physiol Heart Circ Physiol 2007;292:H1139-H1147.

24 Chu W, Li X, Li C, Wan L, Shi H, Song X, Liu X, Chen X, Zhang C, Shan H, Lu Y, Yang B: Tgfbr3, a potential 


\section{Cellular Physiology and Biochemistry}

Cell Physiol Biochem 2015;35:213-226

\begin{tabular}{l|l}
\hline DOI: $10.1159 / 000369689$ & (C) 2015 S. Karger AG, Basel
\end{tabular}

Zhao et al.: MiRNA-101a Targets TGFßRI on CFs

negative regulator of tgf-beta signaling, protects cardiac fibroblasts from hypoxia-induced apoptosis. J Cell Physiol 2011;226:2586-2594.

-25 Sutton MG, Sharpe N: Left ventricular remodeling after myocardial infarction: pathophysiology and therapy. Circulation 2000;101:2981-2988.

-26 Pellman J, Lyon RC, Sheikh F: Extracellular matrix remodeling in atrial fibrosis: mechanisms and implications in atrial fibrillation. J Mol Cell Cardiol 2010;48:461-467.

-27 Creemers EE, Pinto YM: Molecular mechanisms that control interstitial fibrosis in the pressure-overloaded heart. Cardiovasc Res 2011;89:265-272.

28 Devaux Y, Bousquenaud M, Rodius S, Marie PY, Maskali F, Zhang L, Azuaje F, Wagner DR: Transforming growth factor beta receptor 1 is a new candidate prognostic biomarker after acute myocardial infarction. BMC Med Genomics 2011;4:83.

29 Ikeda S, Kong SW, Lu J, Bisping E, Zhang H, Allen PD, Golub TR, Pieske B, Pu WT: Altered microrna expression in human heart disease. Physiol Genomics 2007;31:367-373.

30 van Rooij E, Sutherland LB, Thatcher JE, DiMaio JM, Naseem RH, Marshall WS, Hill JA, Olson EN: Dysregulation of micrornas after myocardial infarction reveals a role of mir-29 in cardiac fibrosis. Proc Natl Acad Sci U S A 2008;105:13027-13032.

-31 Devaux Y, Vausort M, McCann GP, Kelly D, Collignon O, Ng LL, Wagner DR, Squire IB: A panel of 4 micrornas facilitates the prediction of left ventricular contractility after acute myocardial infarction. PLoS One 2013;8:e70644.

-32 Devaux Y, Vausort M, McCann GP, Zangrando J, Kelly D, Razvi N, Zhang L, Ng LL, Wagner DR, Squire IB: Microrna-150: a novel marker of left ventricular remodeling after acute myocardial infarction. Circ Cardiovasc Genet 2013;6:290-298.

- 33 Kim JH, Lee KS, Lee DK, Kim J, Kwak SN, Ha KS, Choe J, Won MH, Cho BR, Jeoung D, Lee H, Kwon YG, Kim YM: Hypoxia-responsive microrna-101 promotes angiogenesis via heme oxygenase-1/vegf axis by targeting cullin 3. Antioxid Redox Signal 2014

34 Bauersachs J, Thum T: Biogenesis and regulation of cardiovascular micrornas. Circ Res 2011;109:334-347.

- 35 Shan H, Zhang Y, Lu Y, Zhang Y, Pan Z, Cai B, Wang N, Li X, Feng T, Hong Y, Yang B: Downregulation of mir-133 and mir-590 contributes to nicotine-induced atrial remodelling in canines. Cardiovasc Res 2009;83:465-472.

36 Tu X, Zhang H, Zhang J, Zhao S, Zheng X, Zhang Z, Zhu J, Chen J, Dong L, Zang Y, Zhang J: Microrna-101 suppresses liver fibrosis by targeting the tgfbeta signalling pathway. J Pathol 2014

-37 Duisters RF, Tijsen AJ, Schroen B, Leenders JJ, Lentink V, van der Made I, Herias V, van Leeuwen RE, Schellings MW, Barenbrug P, Maessen JG, Heymans S, Pinto YM, Creemers EE: Mir-133 and mir-30 regulate connective tissue growth factor: implications for a role of micrornas in myocardial matrix remodeling. Circ Res 2009;104:170-178, 6p-178p.

- 38 Weber KT, Sun Y, Bhattacharya SK, Ahokas RA, Gerling IC: Myofibroblast-mediated mechanisms of pathological remodelling of the heart. Nat Rev Cardiol 2013;10:15-26.

-39 Ma Y, de Castro BL, Toba H, Iyer RP, Hall ME, Winniford MD, Lange RA, Tyagi SC, Lindsey ML: Myofibroblasts and the extracellular matrix network in post-myocardial infarction cardiac remodeling. Pflugers Arch 2014;466:1113-1127.

-40 Goldsmith EC, Bradshaw AD, Zile MR, Spinale FG: Myocardial fibroblast-matrix interactions and potential therapeutic targets. J Mol Cell Cardiol 2014;70:92-99.

-41 Virag JI, Murry CE: Myofibroblast and endothelial cell proliferation during murine myocardial infarct repair. Am J Pathol 2003;163:2433-2440.

42 Leask A: Tgfbeta, cardiac fibroblasts, and the fibrotic response. Cardiovasc Res 2007;74:207-212.

43 Sakata Y, Chancey AL, Divakaran VG, Sekiguchi K, Sivasubramanian N, Mann DL: Transforming growth factor-beta receptor antagonism attenuates myocardial fibrosis in mice with cardiac-restricted overexpression of tumor necrosis factor. Basic Res Cardiol 2008;103:60-68.

-44 Driesen RB, Nagaraju CK, Abi-Char J, Coenen T, Lijnen PJ, Fagard RH, Sipido KR, Petrov VV: Reversible and irreversible differentiation of cardiac fibroblasts. Cardiovasc Res 2014;101:411-422.

45 Wang B, Jha JC, Hagiwara S, McClelland AD, Jandeleit-Dahm K, Thomas MC, Cooper ME, Kantharidis P: Transforming growth factor-beta1-mediated renal fibrosis is dependent on the regulation of transforming growth factor receptor 1 expression by let-7b. Kidney Int 2014;85:352-361.

46 Kang JS, Liu C, Derynck R: New regulatory mechanisms of tgf-beta receptor function. Trends Cell Biol 2009;19:385-394. 